\title{
Thrombosis in Inherited Fibrinogen Disorders
}

\author{
Wolfgang Korte ${ }^{a}$ Man-Chiu Poon ${ }^{b}$ Alfonso lorio ${ }^{c}$ Michael Makris ${ }^{d, e}$ \\ ${ }^{a}$ Center for Laboratory Medicine; and Hemostasis and Hemophilia Center St. Gallen, Switzerland; \\ ${ }^{b}$ Departments of Medicine, Pediatrics and Oncology, University of Calgary, Southern Alberta Rare Blood and Bleeding Disorders \\ Comprehensive Care Program, Foothills Hospital, Calgary, AB, Canada; \\ ${ }^{\mathrm{C}}$ Department of Medicine, McMaster University, Hamilton, ON, Canada; \\ dSheffield Haemophilia and Thrombosis Centre, Royal Hallamshire Hospital, Sheffield, UK; \\ e Department of Infection, Immunity and Cardiovascular Disease, University of Sheffield, Sheffield, UK
}

\section{Keywords}

Blood coagulation disorders · Inherited · Congenital · Fibrinogen · Hemorrhage $\cdot$ Thrombosis

\section{Summary}

Although inherited fibrinogen disorders (IFD) are primarily considered to be bleeding disorders, they are associated with a higher thrombotic complication risk than defects in other clotting factors. Managing IFD patients with thrombosis is challenging as anticoagulant treatment may exacerbate the underlying bleeding risk which can be life-threatening. Due to the low prevalence of IFD, there is little information on pathophysiology or optimal treatment of thrombosis in these patients. We searched the literature for cases of thrombosis among IFD patients and identified a total of 128 patient reports. In approximately half of the cases, thromboses were spontaneous, while in the others trauma, surgery, and parturition contributed to the risk. The true mechanism(s) of thrombosis in IFD patients remain to be elucidated. A variety of anticoagulant treatments have been used in the treatment or prevention of thrombosis, sometimes with concurrent fibrinogen replacement therapy. There is no definite evidence that fibrinogen supplementation increases the risk of thrombosis, and it may potentially be effective in the treatment and prevention of both thrombosis and hemorrhage in IFD patients.

(C) 2017 S. Karger GmbH, Freiburg

\section{Introduction}

Fibrinogen plays a key role in the process of coagulation. It functions not only as the precursor of the fibrin net that gives structure to blood clots but also as a promoter of platelet aggregation and fibrinolysis. Two types of inherited fibrinogen disorder (IFD) are recognized, both of which are rare: Type I involves reduced quantities of fibrinogen, whilst type II involves qualitative abnormality. Type I IFD includes afibrinogenemia (absence of fibrinogen, plasma level $<0.1 \mathrm{~g} / \mathrm{l}$ ) and hypofibrinogenemia (low plasma levels of fibrinogen, $0.1-1.5 \mathrm{~g} / \mathrm{l}$ ), while type II encompasses dysfibrinogenemia (normal fibrinogen levels (1.5-3.5 g/l) with low functional activity) $[1,2]$. A small number of patients have both hypofibrinogenemia and dysfibrinogenemia, and this condition is described as hypodysfibrinogenemia. IFD is considered as rare on the basis that afibrinogenemia and dysfibrinogenemia each have an estimated prevalence of one in 1,000,000 [1-3], although the frequency of hypofibrinogenemia is believed to be higher [1].

Increased bleeding is generally considered as the primary manifestation of IFD, with umbilical cord bleeding affecting as many as $85 \%$ of neonates with afibrinogenemia [4]. Patients with hypofibrinogenemia and dysfibrinogenemia have a lower risk of bleeding events, but these individuals are still at higher risk than the general population, for example during surgery or pregnancy [5].

Despite the deficiency of fibrinogen, there is a potential risk of thromboembolic complications among IFD patients [6, 7]. Managing IFD patients with thrombosis is challenging as they may be at risk of life-threatening hemorrhage [8] or require hemostatic support following surgery, trauma, or childbirth $[9,10]$. In such situations, clinicians face the difficult task of providing sufficient hemostasis while minimizing the risk of thromboembolism. Due to the low prevalence of IFD, there is little information on pathophysiology or optimal treatment of thrombosis in these patients. 


\section{Literature Review}

In order to obtain more information about thrombosis in IFD patients, we searched the PubMed database on September 21, 2015 using the terms 'congenital fibrinogen deficiency', 'afibrinogenemia', 'dysfibrinogenemia' or 'hypofibrinogenemia' in combination with the terms 'thrombotic', 'thrombosis' or 'emboli*' to identify relevant case reports and clinical studies. This yielded a total of 490 results. Based on titles and abstracts, we identified 86 potentially relevant publications. Further full-text examination of these publications identified 62 case reports of patients with IFD experiencing thrombotic symptoms. We also identified 8 clinical studies or case series ( $>3$ patients) that included reports of thrombosis among IFD patients. However, these publications provide minimal information on the individual patients concerned or the circumstances in which thrombosis occurred, for example using the word 'thromboembolism' without providing any additional details.

The case reports are summarized in supplemental table 1 (available at http://content.karger.com/ProdukteDB/produkte.asp?doi= 452864): 72 patients with thrombotic events were described in the 62 publications. A summary of data from the clinical studies and case series is presented in table 1 . A total of 56 patients experiencing at least one thrombotic episode are described. Consequently, the total number of IFD patients with thrombosis is 128.25 patients were diagnosed with afibrinogenemia, 79 with dysfibrinogenemia, 16 with hypofibrinogenemia, and 6 with hypodysfibrinogenemia. Venous thrombosis appears to be the most common thrombotic event, having been reported in 74 patients (58\%). In 35 of these cases ( $27 \%$ of the overall population), pulmonary embolism was the manifestation. Arterial thrombosis was reported in 31 patients (24\%). In a small number of patients $(n=5)$, combinations of venous and arterial events occurred at the same time. There were also a number of reports of ischemia and necrosis where it could not be clearly established whether the cause was venous or arterial thrombosis. Thromboses occurred in a variety of different locations, including the legs, vena cava, portal system, and pulmonary artery.

In a large European case series of patients with dysfibrinogenemia $(n=101)$, the age- and sex-adjusted risk of thrombotic events after diagnosis of dysfibrinogenemia was $18.7 / 1,000$ patient years [7]. The overall risk of thrombotic events did not differ between men and women, and the cumulative incidence of thrombotic events at the age of 50 years was estimated to be $30.1 \%$ (95\% confidence interval, 20.1-43.5\%). A large study of Chinese cases included retrospective analysis of clinical manifestations among 102 individuals with dysfibrinogenemia; thrombosis was reported in 4 of these patients (3.9\%) [11].

\section{Risk Factors for Thrombosis}

In 22 of the 72 case reports (31\%), thrombosis developed after a surgical procedure, parturition, or trauma. This suggests that, as in the general population, such events can precipitate thrombosis among individuals with IFD, including those without previous history of thrombosis. Epidemiological risk factors for thrombosis include smoking, hypertension, obesity, and the use of oral contraceptives [12-14]. Such risk factors were present in 9 of the cases that we identified (13\%), with some patients having more than one risk factor. Furthermore, in 4 cases (6\%) factor V Leiden mutation was present as a thrombophilic risk. Despite these observations, approximately half of thromboses appear to have occurred in the absence of surgery/trauma or epidemiological risk factors, meaning that IFD itself was the probable cause.

In the large European case series of dysfibrinogenemia patients, the authors examined whether there was a relationship between plasma fibrinogen levels and thrombotic risk [7]. No such relationship was found, with respect to either fibrinogen activity or fibrinogen activity-antigen ratio where available.

One question of interest is whether fibrinogen substitution constitutes a risk factor for thromboembolism in IFD patients. Of the patients presented in table 1, 44\% (32 out of 72) had previously received fibrinogen supplementation with therapeutic plasma, cryoprecipitate, or fibrinogen concentrate before thrombosis. However, there are reports of a number of patients who had been receiving fibrinogen for many years without experiencing any thrombotic symptoms [15-17] while others showed a different course. Some experienced onset of thrombotic symptoms after more than a year of being off fibrinogen [17] or experienced thrombosis before as well as after receiving fibrinogen [18]. A close temporal relationship between the administration of fibrinogen concentrate and the development of thrombotic events was observed mainly in cases where fibrinogen was administered as perioperative hemostatic management $[9,19,20]$. In one of these cases, the patient had also had a thrombotic stroke prior to surgery and fibrinogen infusion [20]. Thrombotic events also developed postoperatively when cryoprecipitate was used to maintain fibrinogen levels [10, 21]. Given the small number of cases and the broad range of clinical circumstances, it is not possible to conclude from the case reports that any form of fibrinogen replacement increases the risk of thrombotic events.

\section{Pathophysiology of Thrombosis in Inherited Fibrinogen Disorders}

IFD, particularly certain forms of dysfibrinogenemia, is associated with increased risk of thrombosis [5]. Such a relationship may appear counterintuitive, considering that fibrinogen serves as a primary substrate of coagulation. One hypothesis for the increased thrombotic risk is that concentrations of circulating thrombin are increased in fibrinogen deficiency $[22,23]$. In the past, fibrin has been described as antithrombin I due to its ability to bind thrombin [24]. Thrombin is sequestered by the fibrin clot as it forms, reducing the amount of free thrombin in the circulation [23]. This in vivo clearance mechanism does not occur in patients with afibrinogenemia. Free thrombin remaining unbound to fibrin is not contained locally [25], and its potential effects include platelet activa- 


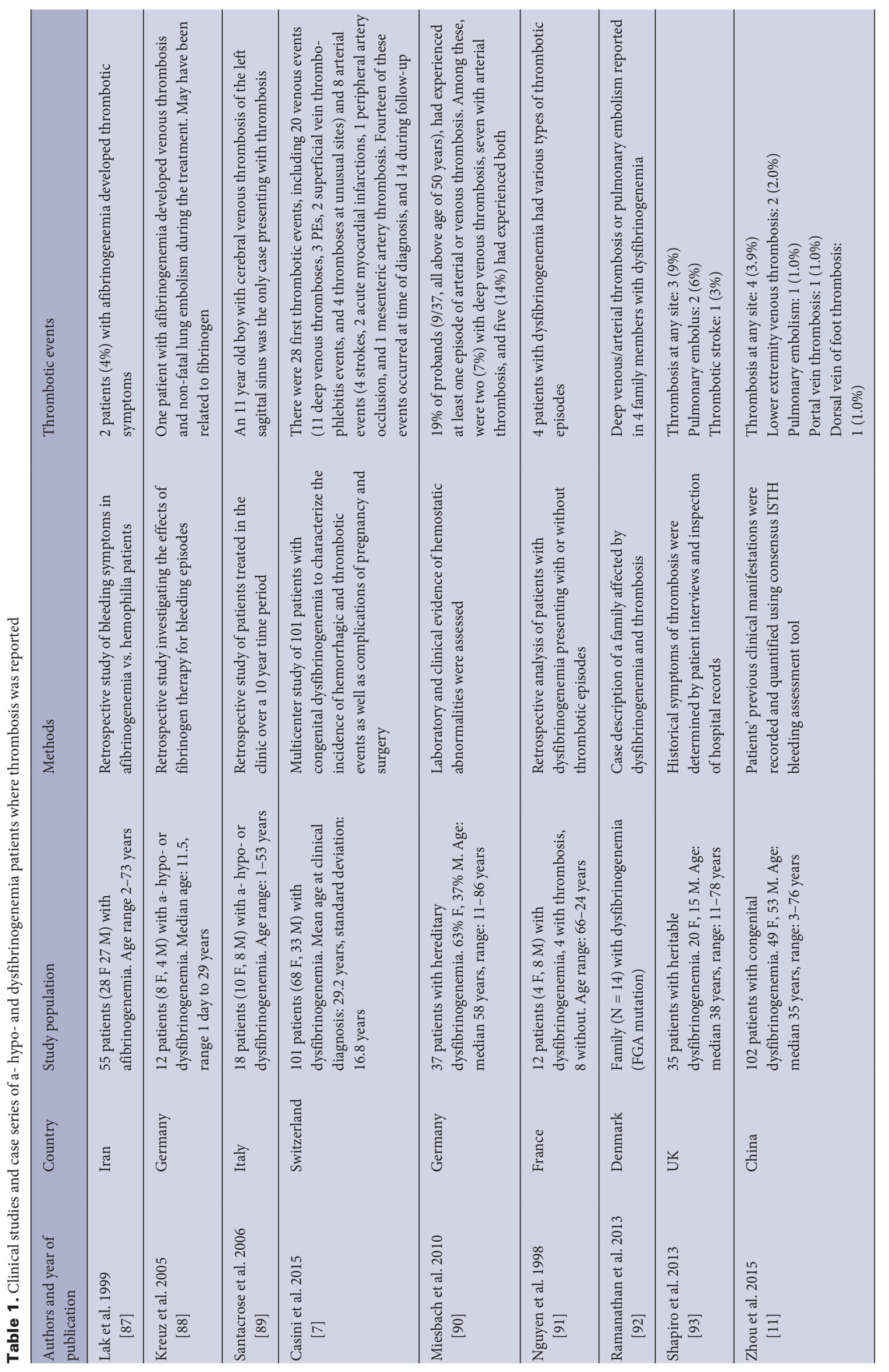


tion [23]. It has also been shown that fibrin can down-regulate thrombin generation [22]. Therefore, a reduction or absence of functional fibrinogen could directly increase thrombin activity.

Soluble fibrinogen competitively inhibits normal platelet adhesion to immobilized fibrinogen [26]. Accordingly, experiments suggest that adhesion of normal platelets suspended in afibrinogenemic plasma to immobilized fibrinogen is high and that this can be reversed by soluble fibrinogen [26]. The addition of von Willebrand factor (vWF) to afibrinogenemic platelet-rich plasma supports platelet aggregation induced by adenosine diphosphate (ADP) [27]. This suggests that vWF may potentially play a compensatory role in the absence of fibrinogen.

Thrombus formation has been shown to occur in mice lacking fibrinogen and vWF. The thrombi that formed in this model were unstable and, as a consequence, detached from the subendothelium of the arterioles where they formed [28]. Translocation and embolization of the thrombi led to downstream occlusion of blood vessels.

The mechanisms above suggest that the absence of fibrinogen may lead to increased levels of other procoagulants, and this could increase patients' prothrombotic tendency. Fibrinogen substitution aimed at normalizing fibrinogen levels may, potentially, reverse the compensatory adjustments and reduce prothrombotic tendency.

In patients with dysfibrinogenemia, thrombosis may be caused by pre-existing risk factors such as antiphospholipid antibody syndrome or by certain mutations in the fibrinogen gene. For example, in Dusart syndrome the mutation A- $\alpha 554$ arginine $\rightarrow$ cysteine increases the brittleness of blood clots so that they break easily and cause embolism [29]. Another mutation, B $\beta$ Ala98(68)Thr, prevents thrombin from binding to fibrin, leading to an increase in the level of free thrombin in the blood [11]. A variety of alterations in the strength, structure, or stability of the fibrin clot may potentially lead to the occurrence of thrombosis $[7,30]$.

Overall, despite the identification of several factors which may contribute to thrombosis in patients with IFD, the exact mechanism(s) behind each clinical occurrence are yet to be elucidated.

\section{Prevention of Thrombosis}

The key to optimal management of patients with IFD is to achieve an appropriate balance between pro- and anticoagulant interventions based on the individual patient's laboratory results and clinical presentation. This should enable effective prevention of thrombosis while also maintaining a low risk of hemorrhage. The literature suggests that thromboembolic events are not always preventable, but it should be possible to minimize their occurrence and successfully treat the few cases that still occur. IFD patients with underlying thrombotic risk(s) may potentially be susceptible to thrombotic complications when hemostasis is normalized by replacement therapy.

A number of therapeutic options have been explored for the prevention of thrombosis in patients with IFD. The principal options are briefly reviewed below.

\section{Anticoagulant Therapy}

Administration of low-molecular-weight heparin (LMWH, enoxaparin) has been advocated in advance of surgery for IFD patients with a thrombotic phenotype $[1,31]$. In afibrinogenemia, LMWH (15,000 anti-factor Xa activity units twice daily) has been used to prevent thromboembolism [32]. LMWH thromboprophylaxis has also been pursued in dysfibrinogenemia [33]. Some authors have suggested administering small doses of heparin alongside fibrinogen therapy $[1,2]$.

Other anticoagulant drugs have also been used, including vitamin K antagonists, factor Xa inhibitors, and aspirin. Supplemental table 1 (available at http://content.karger.com/ProdukteDB/produkte. asp?doi=452864) provides an indication of the extent to which these treatments have been used in patients experiencing thrombosis.

\section{Fibrinogen Replacement Therapy}

Fibrinogen replacement therapy is often employed for the treatment or prevention of bleeding in patients with IFD. Despite the focus on bleeding, fibrinogen replacement therapy can also affect the risk of thrombosis. It has previously been suggested that increased risk of thrombotic complications may be an inherent risk of fibrinogen replacement therapy [34]. Thus, a degree of caution is warranted when treating IFD patients with fibrinogen. However, as described above, it is possible that such treatment may reverse procoagulant mechanisms that compensate for fibrinogen deficiency, thereby reducing the pre-existing risk of thrombosis in IFD patients. This perspective was reflected in the conclusions of a recent review of thromboembolism in afibrinogenemia: frequent, low-dose fibrinogen replacement was suggested to be a 'safe and effective' treatment [35]. The options for fibrinogen supplementation include fibrinogen concentrate, cryoprecipitate, and fresh frozen plasma. Fibrinogen concentrate may reduce the risk of thrombosis in IFD patients compared with cryoprecipitate because, unlike cryoprecipitate and plasma, it does not contain coagulation factors other than fibrinogen (e.g. factor VIII, vWF) $[5,32,36]$. In afibrinogenemia with elevated prothrombin activation, fibrinogen concentrate has been shown to reduce the level of prothrombin activation [37]. Compared with therapeutic plasma, cryoprecipitate and fibrinogen concentrate may be considered as preferable because of reduced infusion volumes [5].

For severe bleeding or major surgery, a target plasma fibrinogen level of $>1.0 \mathrm{~g} / \mathrm{l}$ is recommended, which may be achieved with a fibrinogen dose of $50-100 \mathrm{mg} / \mathrm{kg}$ followed by smaller doses every $2-4$ days $[1,33]$. Long periods without symptoms are common [1]; as a result, it is common for IFD patients to receive fibrinogen replacement therapy only in response to bleeding episodes. However, for patients with a personal or family history of severe bleeding, long-term prophylaxis may be considered. In this context, administration of fibrinogen is recommended every 7--14 days, with dose adjustment to maintain the plasma fibrinogen concentration above $0.5 \mathrm{~g} / \mathrm{l}[1,4,33]$. In pregnant women with IFD and a history 
of adverse pregnancy outcomes, fibrinogen supplementation twice per week throughout pregnancy should be considered $[4,33]$. Treatment to achieve a higher plasma fibrinogen level (ideally $>2.0$ $\mathrm{g} / \mathrm{l}$ ) is recommended during labor [4].

\section{Treatment of Thrombosis}

Supplemental table 1 (available at http://content.karger.com/ ProdukteDB/produkte.asp?doi=452864) shows that a broad array pharmacotherapeutic options has been used for the treatment of thrombosis in IFD patients. Reported therapies include anticoagulant, antiplatelet or vasodilatory drugs such as LMWH, rivaroxaban, warfarin, aspirin, clopidogrel, urokinase, phenprocoumon, streptokinase, pentoxifylline, nifedipine, and nafamostat $[15,16,18,38-44]$. Concomitant fibrinogen replacement therapy may be administered to reduce the risk of severe hemorrhage $[16,17,38]$. The choice of specific drugs and whether to initiate concomitant fibrinogen replacement will depend on the specific clinical situation and patient history. In the large case series of patients with dysfibrinogenemia, all patients with venous thromboembolism were treated with anticoagulant therapy for up to 1 year, and antiplatelet medication was given to patients with arterial events [7].

In some instances, pharmacological interventions alone may not be sufficient. Surgical interventions, including thrombus removal, resection and inferior vena cava filter placement, may be considered. Favorable outcomes have been reported with both pharmacotherapy and surgery in the majority of patients $[19,41$, 42]. In 7 cases (10\%), the thrombotic event was fatal, while the rest made a full recovery.

\section{Conclusion}

Although thrombosis in IFD patients is uncommon, it is well reported in the literature. Known risk factors such as surgery, trauma, and parturition increase the likelihood of thrombosis, whilst in approximately half of the cases the thrombotic event was spontaneous. The true mechanism(s) of thrombosis in IFD patients remain to be elucidated. Although it has been suggested that fibrinogen treatment may be a risk factor for thrombosis, the published data do not support this notion. Compensatory regulation of other clotting factors among IFD patients may be reversed by fibrinogen replacement therapy, potentially decreasing the risk of thrombosis. Managing thrombosis in IFD patients is challenging because of the need to balance the need for anticoagulation with the risk of hemorrhage. Fibrinogen supplementation may be effective for the treatment and prevention of both thrombosis and hemorrhage in IFD patients.

\section{Acknowledgments}

Development of this manuscript was funded by CSL Behring. Medical writing and editorial assistance with manuscript preparation was provided by $\mathrm{Me}$ ridian HealthComms Ltd, funded by CSL Behring.

\section{Disclosure Statement}

WK has received speaker fees, travel support and research support from CSL Behring, Novo Nordisk and Baxter, and he has provided advisory services for Octapharma. MCP has received consultancy fees from Novo Nordisk, CSL Behring, Bayer, Baxalta, Pfizer, Biogen-Idec, and Octapharma; he has also received grant support from CSL-Behring and Bayer, as well as serving as study investigator for CSL Behring. AI declares no potential conflicts of interest. MM has acted as consultant to Novo Nordisk and CSL Behring; he has also received travel support and his employer has received speaker fees from Baxter, Bayer, Biotest and Biogen.

\section{References}

1 de Moerloose P, Casini A, Neerman-Arbez M: Congenital fibrinogen disorders: an update. Semin Thromb Hemost 2013;39:585-595.

2 Acharya SS, Dimichele DM: Rare inherited disorder of fibrinogen. Haemophilia 2008;14:1151-1158.

3 Mannucci PM, Duga S, Peyvandi F: Recessively inherited coagulation disorders. Blood 2004;104:1243-1252.

4 Peyvandi F: Epidemiology and treatment of congenital fibrinogen deficiency. Thromb Res 2012;130(suppl 2): S7-11.

5 Bornikova L, Peyvandi F, Allen G, Bernstein J, MancoJohnson MJ: Fibrinogen replacement therapy for congenital fibrinogen deficiency. J Thromb Haemost 2011; 9:1687-1704.

6 Chafa O, Chellali T, Sternberg C, Reghis A, Hamladji RM, Fischer AM: Severe hypofibrinogenemia associated with bilateral ischemic necrosis of toes and fingers. Blood Coagul Fibrinolysis 1995;6:549-552.

7 Casini A, Blondon M, Lebreton A, Koegel J, Tintillier V, de Maistre E, Gautier P, Biron C, Neerman-Arbez M, de Moerloose P: Natural history of patients with congenital dysfibrinogenemia. Blood 2015;125:553-561.
8 Chevalier Y, Dargaud Y, Argaud L, Ninet J, Jouanneau E, Negrier C: Successive bleeding and thrombotic complications in a patient with afibrinogenemia: a case report. Thromb Res 2011;128:296-298.

9 Lebreton A, Casini A, Alhayek R, Kouteich KL, Neerman-Arbez M, de Moerloose P: Successful pregnancy under fibrinogen substitution in a woman with congenital afibrinogenaemia complicated by a postpartum venous thrombosis. Haemophilia 2015;21:e108-110.

10 Lefebvre P, Velasco PT, Dear A, Lounes KC, Lord ST, Brennan SO, Green D, Lorand L: Severe hypodysfibrinogenemia in compound heterozygotes of the fibrinogen AalphaIVS4 + 1G>T mutation and an AalphaGln328 truncation (fibrinogen Keokuk). Blood 2004;103:2571-2576.

11 Zhou J, Ding Q, Chen Y, Ouyang Q, Jiang L, Dai J, Lu $\mathrm{Y}, \mathrm{Wu} \mathrm{X}$, Liang Q, Wang $\mathrm{H}$, Wang X: Clinical features and molecular basis of 102 Chinese patients with congenital dysfibrinogenemia. Blood Cells Mol Dis 2015; 55:308-315.
12 Newby DE, Wright RA, Labinjoh C, Ludlam CA, Fox KA, Boon NA, Webb DJ: Endothelial dysfunction, impaired endogenous fibrinolysis, and cigarette smoking a mechanism for arterial thrombosis and myocardial infarction. Circulation 1999;99:1411-1415.

13 Lidegaard Ø: Oral contraceptives, pregnancy and the risk of cerebral thromboembolism: the influence of diabetes, hypertension, migraine and previous thrombotic disease. BJOG 1995;102:153-159.

14 Abdollahi M, Cushman M, Rosendaal FR: Obesity: risk of venous thrombosis and the interaction with coagulation factor levels and oral contraceptive use. Thromb Haemost 2003;89:493-498.

15 Schuepbach RA, Meili EO, Schneider E, Peter U, Bachli EB: Lepirudin therapy for thrombotic complications in congenital afibrinogenaemia. Thromb Haemost 2004;91:1044-1046.

16 Sartori MT, Milan M, de Bon E, Fadin M, Pesavento R, Zanon E: Thrombosis of abdominal aorta in congenital afibrinogenemia: case report and review of literature. Haemophilia 2015;21:88-94. 
17 Castaman G, Lunardi M, Rigo L, Mastroeni V, Bonoldi E, Rodeghiero F: Severe spontaneous arterial thrombotic manifestations in patients with inherited hypoand afibrinogenemia. Haemophilia 2009;15:533-537.

18 Ozdemir MA, Isik B, Patiroglu T, Karakukcu M, Mutlu FT, Yilmaz E, Unal E: A case of congenital afibrinogenemia complicated with thromboembolic events that required repeated amputations. Blood Coagul Fibrinolysis 2015;26:354-356.

19 Haberer JP, Obstler C, Samama CM, Darnige L, Szwebel TA, Meyer A, Horellou MH: Postoperative deep venous thrombosis in a woman with congenital afibrinogenaemia treated with fibrinogen concentrates. Eur J Anaesthesiol 2008;25:519-521.

20 Chun R, Poon MC, Haigh J, Seal D, Donahue B, Royston D: Case 1 - 2005: cardiac surgery in congenital afibrinogenemia with thrombo-occlusive disease. J Cardiothorac Vasc Anesth 2005;19:109-117.

21 Ganti AK, Vose JM, Haire WD: Hematopoietic stem cell transplantation for Hodgkin's disease in a patient with dysfibrinogenemia and thrombosis. J Thromb Thrombolysis 2007;23:155-158.

22 de Bosch NB, Mosesson MW, Ruiz-Saez A, Echenagucia $\mathrm{M}$, Rodriguez-Lemoin A: Inhibition of thrombin generation in plasma by fibrin formation (antithrombin I). Thromb Haemost 2002;88:253-258.

23 Dupuy E, Soria C, Molho P, Zini JM, Rosenstingl S, Laurian C, Bruneval P, Tobelem G: Embolized ischemic lesions of toes in an afibrinogenemic patient possible relevance to in vivo circulating thrombin. Thromb Res 2001;102:211-219.

24 Mosesson MW: Update on antithrombin I (fibrin) Thromb Haemost 2007;98:105-108.

25 Sniecinski RM, Chen EP, Tanaka KA: Reduced levels of fibrin (antithrombin I) and antithrombin III underlie coagulopathy following complex cardiac surgery. Blood Coagul Fibrinolysis 2008; 19:178-179.

26 Endenburg SC, Lindeboom-Blokzijl L, Zwaginga JJ Sixma JJ, de Groot PG: Plasma fibrinogen inhibits platelets adhesion in flowing blood to immobilized fibrinogen. Arterioscler Thromb Vasc Biol 1996;16:633-638.

27 De Marco L, Girolami A, Zimmerman TS, Ruggeri ZM: von Willebrand factor interaction with the glycoprotein IIb/IIa complex. Its role in platelet function as demonstrated in patients with congenital afibrinogenemia. J Clin Invest 1986;77:1272-1277.

$28 \mathrm{Ni} \mathrm{H}$, Denis CV, Subbarao S, Degen JL, Sato TN, Hynes RO, Wagner DD: Persistence of platelet thrombus formation in arterioles of mice lacking both von Willebrand factor and fibrinogen. J Clin Invest 2000; 106:385-392.

29 Collet JP, Soria J, Mirshahi M, Hirsch M, Dagonnet FB, Caen J, Soria C: Dusart syndrome: a new concept of the relationship between fibrin clot architecture and fibrin clot degradability: hypofibrinolysis related to an abnormal clot structure. Blood 1993;82:2462-2469.

30 Ariens RA: Fibrin(ogen) and thrombotic disease. J Thromb Haemost 2013;11(suppl 1):294-305.

31 de Moerloose P, Neerman-Arbez M: Congenital fibrinogen disorders. Semin Thromb Hemost 2009;35:356366

32 Henselmans JM, Meijer K, Haaxma R, Hew J, van der Meer J: Recurrent spontaneous intracerebral hemorrhage in a congenitally afibrinogenemic patient: diagnostic pitfalls and therapeutic options. Stroke 1999;30 2479-2482.

33 Mumford AD, Ackroyd S, Alikhan R, Bowles L, Chowdary P, Grainger J, Mainwaring J, Mathias M, O'Connell N, Committee B: Guideline for the diagnosis and management of the rare coagulation disorders: a United Kingdom Haemophilia Centre Doctors' Organization guideline on behalf of the British Committee for Standards in Haematology. Br J Haematol 2014; 167:304-326.
34 de Moerloose P, Neerman-Arbez M: Treatment of congenital fibrinogen disorders. Expert Opin Biol Ther 2008;8:979-992.

35 Nagler M, Kremer Hovinga JA, Alberio L, PeterSalonen K, von Tengg-Kobligk H, Lottaz D, NeermanArbez M, Lammle B: Thromboembolism in patients with congenital afibrinogenaemia. Long-term observational data and systematic review. Thromb Haemost 2016;116:722-732.

36 Peyvandi F, Haertel S, Knaub S, Mannucci PM: Incidence of bleeding symptoms in 100 patients with inherited afibrinogenemia or hypofibrinogenemia. J Thromb Haemost 2006;4:1634-1637.

37 Korte W, Feldges A: Increased prothrombin activation in a patient with congenital afibrinogenemia is reversible by fibrinogen substitution. Clin Investig 1994;72: 396-398.

38 Margaglione M, Vecchione G, Cappucci F, Macarini L, D’Andrea G, Di Matteo C, Grandone E: Venous thrombosis in afibrinogenemia: a successful use of rivaroxaban. Haemophilia 2015;21:e431-433.

39 Cheah CY, Brennan SO, Kennedy H, Januszewicz EH, Maxwell E, Burbury K: Fibrinogen Melbourne: a novel congenital hypodysfibrinogenemia caused by gamma326Cys-Phe in the fibrinogen gamma chain, presenting as massive splanchnic venous thrombosis. Blood Coagul Fibrinolysis 2012;23:563-565.

40 Kumar N, Padma Kumar R, Ramesh B, Garg N: Afibrinogenaemia: a rare cause of young myocardial infarct. Singapore Med J 2008;49:e104-106.

41 Wulf GG, Unterhalt M, Buchwald A, Zenker D, Kreuzer H, Hiddemann W: Hypercoagulability in a patient with hypodysfibrinogenemia: implications for clinical management. Acta Haematol 1999;101:209-212.

42 Takala T, Oksa H, Rasi V, Tuimala R: Dysfibrinogenemia associated with thrombosis and third-trimester fetal loss. A case report. J Reprod Med 1991;36:410-412.

43 De Mattia D, Regina G, Giordano P, Del Vecchio GC, Altomare M, Schettini F: Association of congenital afibrinogenemia and $\mathrm{K}$-dependent protein $\mathrm{C}$ deficiency - a case report. Angiology 1993;44:745-749.

44 Hanano M, Takahashi H, Arakawa K, Igarashi Y, Takizawa S, Tatewaki W, Fuse I, Shibata A: Consumption coagulopathy associated with left atrial thrombosis. Hematol Pathol 1991;5:27-31.

45 Chapin J, DeSancho M: Pulmonary embolism in a patient with congenital afibrinogenemia. Haemophilia 2013;19:e380-382.

46 Cronin C, Fitzpatrick D, Temperley I: Multiple pulmonary emboli in a patient with afibrinogenaemia. Acta Haematol 1988;79:53-54.

47 Dickenman RC, Brown HJ, Hiratzka T, Vetne G: Thrombotic thrombocytopenic purpura with associated afibrinogenemia; report of case. J Mich State Med Soc 1955;54:1421-1425.

48 MacKinnon HH, Fekete JF: Congenital afibrinogenemia. Vascular changes and multiple thromboses in duced by fibrinogen infusions and contraceptive medication. Can Med Assoc J 1971;104:597-599.

49 Matsumoto T, Wada H, Tamaru S, Sugimoto Y, Fujieda A, Yamamura K, Kobayashi T, Kaneko T, Yamaguchi M, Nobori T, Katayama N: Central venous catheter-related thrombosis after replacement therapy for intracranial bleeding in a patient with afibrinogenaemia. Haemophilia 2008;14:153-156.

50 Mukaddam A, Patil R, Jadli A, Chandrakala S, Ghosh $\mathrm{K}$, Shetty S: Paradoxical bleeding and thrombosis in a patient with afibrinogenemia and fibrinogen Mumbai mutation. Am J Clin Pathol 2015;143:755-757.

51 Pati S, Kombogiorgas D, Anwar A, Price RF: Spontaneous extra-axial intracranial hemorrhage followed by thrombosis in congenital afibrinogenemia: perioperative management of this rare combination. Surg Neurol 2009;71:689-692.
52 Roque H, Stephenson C, Lee MJ, Funai EF, Popiolek D, Kim E, Hart D: Pregnancy-related thrombosis in a woman with congenital afibrinogenemia: a report of two successful pregnancies. Am J Hematol 2004;76: 267-270.

53 Simsek I, de Mazancourt P, Horellou MH, Erdem H Pay S, Dinc A, Samama MM: Afibrinogenemia resulting from homozygous nonsense mutation in A alpha chain gene associated with multiple thrombotic episodes. Blood Coagul Fibrinolysis 2008;19:247-253.

54 Takasugi Y, Shiokawa Y, Kajikawa R, Oh J, Yamamoto Y, Sakata I, Koga Y: Mesenteric venous thrombosis in a patient with congenital afibrinogenemia and diffuse peritonitis. Ann Hematol 2005;84:129-130.

55 Al-Mondhiry H, Galanakis D: Dysfibrinogenemia and lupus anticoagulant in a patient with recurrent thrombosis. J Lab Clin Med 1987;110:726-733.

56 Bandyopadhyay R, Bandyopadhyay SK, Chatterjee U: Inherited dysfibrinogenaemia presenting with portal vein thrombosis. J Indian Med Assoc 2010;108:180182

57 Borrell M, Gari M, Coll I, Vallve C, Tirado I, Soria JM Sala N, Munoz C, Oliver A, Garcia A, Fontcuberta J: Abnormal polymerization and normal binding of plasminogen and t-PA in three new dysfibrinogenaemias: Barcelona III and IV (gamma Arg 275->His) and Villajoyosa (gamma Arg 275->Cys). Blood Coagul Fibrinolysis 1995;6:198-206.

58 Carrell N, Gabriel DA, Blatt PM, Carr ME, McDonagh $\mathrm{J}$ : Hereditary dysfibrinogenemia in a patient with thrombotic disease. Blood 1983;62:439-447.

59 Castaman G, Ghiotto R, Tosetto A, Rodeghiero F: Bbeta $14 \mathrm{Arg} \rightarrow$ Cys variant dysfibrinogen and its association with thrombosis. J Thromb Haemost 2005;3 409-410.

60 Cransac M, Carles J, Bernard PH, Malavialle P, Freyburger G, Winnock S, Saric J: Heterozygous protein C deficiency and dysfibrinogenemia acquired by liver transplantation. Transpl Int 1995;8:307-311.

61 Engesser L, Koopman J, de Munk G, Haverkate F, Novakova I, Verheijen JH, Briet E, Brommer EJ: Fibrinogen Nijmegen: congenital dysfibrinogenemia associated with impaired t-PA mediated plasminogen activation and decreased binding of t-PA. Thromb Haemost 1988;60:113-120.

62 Fuchs G, Egbring R, Havemann K: Fibrinogen Marburg a new genetic variant of fibrinogen. Blut 1977;34: 107-118.

63 Hessel B, Silveira AM, Carlsson K, Oksa H, Rasi V, Vahtera E, Procyk R, Blomback B: Fibrinogenemia Tampere - a dysfibrinogenemia with defective gelation and thromboembolic disease. Thromb Res 1995;78. 323-339.

64 Jagathesan T, Houston SJ, Evans AD: Axillary vein thrombosis and congenital dysfibrinogenemia in a commercial pilot: a case report. Aviat Space Environ Med 2003;74:981-984.

65 Kamijyo Y, Hirota-Kawadobora M, Yamauchi K, Terasawa F, Honda T, Ikeya M, Okumura N: Analysis of plasmin generation and clot lysis of plasma fibrinogen purified from a heterozygous dysfibrinogenemia, BbetaGly15Cys (Hamamatsu II). Blood Coagul Fibrinolysis 2009;20:726-732.

66 Kotlin R, Reicheltova Z, Maly M, Suttnar J, Sobotkova A, Salaj P, Hirmerova J, Riedel T, Dyr JE: Two cases of congenital dysfibrinogenemia associated with thrombosis - Fibrinogen Praha III and Fibrinogen Plzen. Thromb Haemost 2009;102:479-486.

67 Kotlin R, Reicheltova Z, Suttnar J, Salaj P, Hrachovinova I, Riedel T, Maly M, Oravec M, Kvasnicka J, Dyr JE: Two novel fibrinogen variants in the C-terminus of the beta-chain: fibrinogen Rokycany and fibrinogen Znojmo. J Thromb Thrombolysis 2010;30:311-318. 
68 Niwa K, Mimuro J, Miyata M, Sugo T, Ohmori T, Madoiwa S, Tei C, Sakata Y: Dysfibrinogen Kagoshima with the amino acid substitution gammaThr-314 to Ile: analyses of molecular abnormalities and thrombophilic nature of this abnormal molecule. Thromb Res 2008; 121:773-780.

69 Quattrone A, Colucci M, Donati MB, Meduri M, Mussoni L, Roncaglioni MC, Semeraro N, Carlomagno S, Bonavita V: Stroke in two young siblings with congenital dysfibrinogenemia. Ital J Neurol Sc 1983;4:229-232.

70 Reber P, Furlan M, Henschen A, Kaudewitz H, Barbui T, Hilgard P, Nenci GG, Berrettini M, Beck EA: Three abnormal fibrinogen variants with the same amino acid substitution (gamma 275 Arg-His): fibrinogens Bergamo II, Essen and Perugia. Thromb Haemost 1986;56:401-406.

71 Siebenlist KR, Mosesson MW, Meh DA, DiOrio JP, Albrecht RM, Olson JD: Coexisting dysfibrinogenemia (gammaR275C) and factor V Leiden deficiency associated with thromboembolic disease (fibrinogen Cedar Rapids). Blood Coagul Fibrinolysis 2000;11:293-304.

72 Travlou A, Gialeraki A, Merkouri E, Politou M, Sfyridaki A, Neerman-Arbez M: Coexisting dysfibrinogenemia (gamma Arg275His) and FV Leiden associated with thrombosis (Fibrinogen Crete). Thromb Res 2010;126:e162-164.

73 Wada Y, Lord ST: A correlation between thrombotic disease and a specific fibrinogen abnormality (A alpha 554 Arg- $>$ Cys) in two unrelated kindred, Dusart and Chapel Hill III. Blood 1994;84:3709-3714.

74 Ingram GI, McBrien DJ, Spencer H: Fatal pulmonary embolus in congenital fibrinopenia. Report of two cases. Acta Haematol 1966;35:56-62.

75 Hamano A, Mimuro J, Aoshima M, Itoh T, Kitamura N, Nishinarita S, Takano K, Ishiwata A, Kashiwakura Y, Niwa K, Ono T, Madoiwa S, Sugo T, Matsuda M, Sakata Y: Thrombophilic dysfibrinogen Tokyo V with the amino acid substitution of gammaAla327Thr: formation of fragile but fibrinolysis-resistant fibrin clots and its relevance to arterial thromboembolism. Blood 2004; 103:3045-3050.
76 Ieko M, Sawada K, Sakurama S, Yamagishi I, Isogawa S, Nakagawa S, Satoh M, Yasukouchi T, Matsuda M: Fibrinogen date: congenital hypodysfibrinogenemia associated with decreased binding of tissue-plasminogen activator. Am J Hematol 1991;37:228-233.

77 Rea C, Hunt BJ: Novel management of anticoagulant resistant thrombotic hypodysfibrinogenaemia. Thromb Res 2012;130:785-787.

78 Brennan SO, Mosesson MW, Lowen R, Siebenlist KR, Matsunaga A: Hypofibrinogenaemia resulting from novel single nucleotide deletion at codon Bbeta58 (3404del A) associated with thrombotic stroke in infancy. Thromb Haemost 2006;95:738-739.

79 Bukowski MJ, Koblenzer PJ: Thrombotic thrombocytopenic purpura. Report of a case with the unusual features of hypofibrinogenemia and leukopenia. J Pediatr 1962;60:84-90.

80 de Raucourt E, de Mazancourt P, Maghzal GJ, Brennan SO, Mosesson MW: Fibrinogen Saint-Germain II: hypofibrinogenemia due to heterozygous gamma N345S mutation. Thromb Haemost 2005;94:965-968.

81 Gormsen J: Coexistence of hypofibrinogenaemia and thrombosis. Acta Chir Scand 1961;121:359-366.

82 Marchi R, Walton BL, McGary CS, Lin FC, Ma AD, Pawlinski R, Mackman N, Campbell RA, Di Paola J, Wolberg AS: Dysregulated coagulation associated with hypofibrinogenaemia and plasma hypercoagulability: implications for identifying coagulopathic mechanisms in humans. Thromb Haemost 2012;108:516526.

83 Miljic P, Nedeljkov-Jancic R, Zuvela M, Subota V, Dordevic V: Coexistence of hypofibrinogenemia and factor V Leiden mutation: is the balance shifted to thrombosis? Blood Coagul Fibrinolysis 2014;25:628630

84 Nilsson IM, Nilehn JE, Cronberg S, Norden G: Hypofibrinogenaemia and massive thrombosis. Acta Med Scand 1966;180:65-76
85 Sheen CR, Low J, Joseph J, Kotlyar E, George PM, Brennan SO: Fibrinogen Darlinghurst: hypofibrinogenaemia caused by a W253G mutation in the gamma chain in a patient with both bleeding and thrombotic complications. Thromb Haemost 2006;96:685-687.

86 Taslimi R, Golshani K: Thrombotic and hemorrhagic presentation of congenital hypo/afibrinogenemia. Am J Emerg Med 2011;29:573 e573-575.

87 Lak M, Keihani M, Elahi F, Peyvandi F, Mannucci PM Bleeding and thrombosis in 55 patients with inherited afibrinogenaemia. Br J Haematol 1999; 107:204-206.

88 Kreuz W, Meili E, Peter-Salonen K, Haertel S, Devay J, Krzensk U, Egbring R: Efficacy and tolerability of a pasteurised human fibrinogen concentrate in patients with congenital fibrinogen deficiency. Transfus Apher Sci 2005;32:247-253.

89 Santacroce R, Cappucci F, Pisanelli D, Perricone F, Papa ML, Santoro R, Grandone E, Margaglione M: Inherited abnormalities of fibrinogen: 10-year clinical experience of an Italian group. Blood Coagul Fibrinolysis 2006; 17:235-240.

90 Miesbach W, Scharrer I, Henschen A, Neerman-Arbez M, Spitzer S, Galanakis D: Inherited dysfibrinogenemia: clinical phenotypes associated with five different fibrinogen structure defects. Blood Coagul Fibrinolysis 2010;21:35-40.

91 Nguyen F, Drouet L, Boisseau M, Leger P, Juchet H Bierme R, Cambus JP: Erythrocyte hyperaggregation and thrombogenic dysfibrinogenemia. Clin Hemorheol Microcirc 1998;18:235-243.

92 Ramanathan R, Gram J, Feddersen S, Nybo M, Larsen A, Sidelmann JJ: Dusart Syndrome in a Scandinavian family characterized by arterial and venous thrombosis at young age. Scand J Clin Lab Invest 2013;73:585-590.

93 Shapiro SE, Phillips E, Manning RA, Morse CV, Murden SL, Laffan MA, Mumford AD: Clinical phenotype, laboratory features and genotype of 35 patients with heritable dysfibrinogenaemia. Br J Haematol 2013;160: 220-227. 